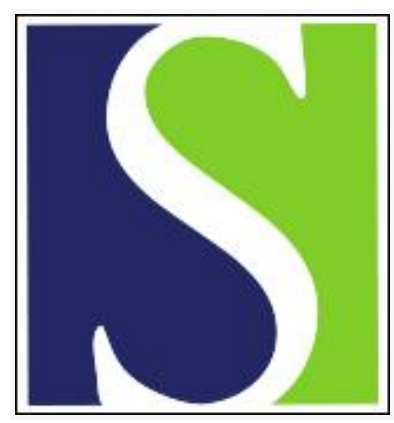

Scand J Work Environ Health 2019;45(4):321-323

https://doi.org/10.5271/sjweh.3838

Published online: 12 Jun 2019, Issue date: 01 Jul 2019

How can we break the vicious circle between poor health and exit from paid employment?

by van $\operatorname{der}$ Beek AJ, Kunst AE

Affiliation: Amsterdam UMC, Vrije Universiteit, Department of Public and Occupational Health, Amsterdam Public Health Research Institute, Amsterdam, The Netherlands. a.vanderbeek@vumc.nl

Refers to the following texts of the Journal: 2019;45(4):346-355

2019;45(2):114-125 2015;41(1):54-64

The following articles refer to this text: 2021;47(1):15-21;

2020;46(5):457-460; 2021;47(3):224-232

Key terms: chronic disease; disability benefit; economic inactivity; editorial; exit from paid employment; labor force exit; leaving the labor force; poor health; retirement; unemployment

This article in PubMed: www.ncbi.nlm.nih.gov/pubmed/31187870 


\section{How can we break the vicious circle between poor health and exit from paid employment?}

People who involuntarily leave the labor market due to health problems run the risk of entering into a vicious circle as exiting the labor market can aggravate their initial health problems, especially if accompanied by other forms of social exclusion. While this problem affects large parts of the population, especially during economic downturns, it may particularly affect those with a weak initial labor market position, such as those with low socioeconomic status (SES). This unequal burden has been documented in an interesting paper in this issue of the Scandinavian Journal of Work, Environment \& Health (1). The authors report findings from five European regions showing that lower-educated persons had increased risks of exit from paid employment due to health problems compared to those with higher education levels.

To document these inequalities, the authors applied a method, the population attributable fraction (PAF), which has a long tradition in public health research but remains underutilized in studies focusing on occupational health. The PAF combines information on the prevalence of the exposure of interest (in this case: poor health), with estimates on the relative risk of those exposed for the outcome of interest (in this case: exit from paid employment). Using the PAF, the authors estimated that the annual rate of labor market exit due to health problems was, for example, about $4 \%$ for intermediate-educated workers in the Continental region. This risk varied considerably according to educational level. For example, in the Continental region, it was about $2 \%$ for higher-educated workers and almost $10 \%$ for lower-educated workers [see figure 2 in (1)].

One might expect this inequality to originate to an important extent from the fact that the risk to exit paid employment due to health problems is lower for those with high versus low SES. For example, higher-educated office workers with knee osteoarthritis $(\mathrm{OA})$ are able to continue working in their job, while lower-educated laborers, who lay street pavements in a kneeling position for a substantial part of their working day, are unable to do so when suffering from 0 A. However, this expectation was not confirmed. The authors found that relative risks to exit paid employment in case of health problems were quite similar for higher- and lower-educated workers, for reasons to be disentangled in future research. Instead, the socioeconomic inequalities in risk of exit from paid employment were primarily due to inequalities in the prevalence of poor health, with lower-educated workers having a much higher prevalence of poor self-rated health than those with a higher education. This raises the key question of how these socioeconomic inequalities in health emerge and how they can be addressed in occupational settings.

Socioeconomic inequalities in self-rated health are considered to originate from a combination of material, psychosocial, and behavioral factors. The materialist explanation includes not only differences in financial resources but also worse living/housing conditions, more insecure employment status, and greater exposure to unhealthy working conditions among persons with a lower SES. The psychosocial explanation takes into account not only that negative life events and chronic strain are more common among people with low SES but also that low mastery, coping or social support are unequally distributed and thus contribute to social inequalities in health. The behavioral explanation emphasizes that unhealthy behaviors, such as smoking, substance use, low physical activity, and poor dietary habits, are more prevalent among people with lower SES.

Moor and colleagues' systematic review (2) showed that all three factors contributes to explaining the socioeconomic inequalities in self-rated health. However, material factors were most important since these factors contributed to health inequalities not only through direct effects on health but also through indirect effects via psychosocial and behavioral factors. For example, an occupational setting might facilitate smoking behavior more among low compared to high SES workers through differences in company culture, influences from close colleagues, and actual opportunities to smoke at work. A review recently published in the Scandinavian Journal of Work, Environment \& Health (3) found that work factors explained about one-third and lifestyle factors about 
one-fifth of socioeconomic inequalities in self-rated health. Schuring et al (1) also stress that physical working conditions and/or psychosocial work characteristics play a substantial role in socioeconomic inequalities in selfrated health (4). If this is indeed the case, then preventive interventions at work might have potential in reducing socioeconomic health inequalities.

In many countries, socioeconomic health inequalities represents one of the most critical public health challenges. Even though measures are being taken to address these inequalities, in practice, uptake of preventive interventions remains larger among people with high compared to low SES. The occupational setting provides particular challenges and opportunities. Physical working conditions and psychosocial work characteristics are critical to the health of workers with lower SES in two ways by: (i) causing ill-health among highly exposed workers with low SES and (ii) acting as obstacles to work for these workers in case of illness. Hence, one might argue that interventions within the occupational setting have the potential to prevent or break the vicious circle between poor health and non-employment. Successful interventions may directly improve health by effects of the intervention itself but also decrease the risk of exit from employment (1), which subsequently leaves healthenhancing effects of employment active for a longer period of time (5).

Workplace interventions specifically aimed at workers with lower SES may focus on the physical or psychosocial work environmental level, the individual worker level, or a combination of both. There is evidence for the effectiveness of environmental-level interventions aiming to improve physical working conditions/ergonomics $(e g, 6)$ as well as those aiming to improve psychosocial work characteristics (7). For the individual level, scientific evidence ranges from physical activity interventions targeted at lower-educated occupational groups in general (8) to interventions focusing on specific branches of industry employing mostly lower-educated blue-collar workers, such as in the meat processing (9), construction (10), or transportation (11) industries. In general, intensive interventions tailored to the lower SES target group are far more promising than low-intensity, generic interventions using a one-size-fits-all approach. To date, however, it remains uncertain how worksite health promotion programs or interventions improving working conditions can be implemented in companies and branches of industry such that workers with lower SES optimally benefit. Therefore, our most important challenge lies in developing such programs and interventions, thus contributing to greater socioeconomic equality in chances for good health as well as paid employment.

\section{References}

1. Schuring M, Schram JLD, Robroek SJW, BurdorfA. The contribution of health to educational inequalities in exit from paid employment in five European regions. Scand J Work Environ Health. 2019;45(4):346-355. https://doi.org/10.5271/sjweh.3796

2. Moor I, Spallek J, Richter M. Explaining socioeconomic inequalities in self-rated health: a systematic review of the relative contribution of material, psychosocial and behavioural factors. J Epidemiol Community Health 2017;71:565-75. https://doi.org/10.1136/jech-2016207589

3. Dieker ACM, IJzelenberg W, Proper KI, Burdorf A, Ket JCF, van der Beek AJ, Hulsegge G. The contribution of work and lifestyle factors to socioeconomic inequalities in self-rated health - a systematic review. Scand J Work Environ Health 2019;45:114-25. https://doi.org/10.5271/sjweh.3772

4. Hoven H, Siegrist J. Work characteristics, socioeconomic position and health: a systematic review of mediation and moderation effects in prospective studies. Occup Environ Med 2013;70:663-9. https://doi.org/10.1136/oemed-2012-101331

5. van der Noordt M, IJzelenberg H, Droomers M, Proper KI. Health effects of employment: a systematic review of prospective studies. Occup Environ Med 2014;71:730-6. https://doi.org/10.1136/oemed-2013-101891

6. Driessen MT, Proper KI, van Tulder MW, Anema JR, Bongers PM, van der Beek AJ. The effectiveness of physical and organizational ergonomic interventions on low back pain and neck pain: a systematic review. Occup Environ Med 2010;67:277-285. https://doi. org/10.1136/oem.2009.047548 
7. Bambra C, Gibson M, Sowden AJ, Wright K, Whitehead M, Petticrew M. Working for health? Evidence from systematic reviews on the effects on health and health inequalities of organisational changes to the psychosocial work environment. Prev Med 2009;48:454-61. https://doi.org/10.1016/j.ypmed.2008.12.018

8. Cairns JM, Bambra C, Hillier-Brown FC, Moore HJ, Summerbell CD. Weighing up the evidence: a systematic review of the effectiveness of workplace interventions to tackle socio-economic inequalities in obesity. J Public Health (Oxf) 2015;37:659-70. https://doi. org/10.1093/pubmed/fdu077

9. van Holland BJ, Soer R, de Boer MR, Reneman MF, Brouwer S. Preventive occupational health interventions in the meat processing industry in upper-middle and high-income countries: a systematic review on their effectiveness. Int Arch Occup Environ Health 2015;88:389-402. https://doi.org/10.1007/s00420-014-0964-3

10. Groeneveld IF, Proper KI, van der Beek AJ, van Mechelen W. Sustained body weight reduction by an individual-based lifestyle intervention for workers in the construction industry at risk for cardiovascular disease: Results of a randomized controlled trial. Prev Med 2010;51:240-6. https://doi.org/10.1016/j.ypmed.2010.07.021

11. Puhkala J. Kukkonen-Harjula K, Mansikkamäki K, Aittasalo M, Hublin C, Kärmeniemi P, et al. Lifestyle counseling to reduce body weight and cardiometabolic risk factors among truck and bus drivers - a randomized controlled trial. Scand J Work Environ Health 2015;41:54-64. https://doi.org/10.5271/sjweh.3463

Prof Allard J van der Beek, PhD

Amsterdam UMC, Vrije Universiteit Amsterdam

Department of Public and Occupational Health Amsterdam Public Health Research Institute

Amsterdam

The Netherlands

a.vanderbeek@vumc.nl
Prof Anton E Kunst, PhD

Amsterdam UMC, University of Amsterdam

Department of Public Health

Amsterdam Public Health Research Institute

Amsterdam

The Netherlands

a.kunst@amc.uva.nl 
